\title{
Confidencialidad de los datos del NIÑO POR PARTE DE LOS PSICÓLOGOS QUE TRABAJAN EN INSTITUCIONES EDUCATIVAS
}

\author{
CONFIDENTIALITY OF CHILDREN'S DATA \\ FOR PSYCHOLOGISTS WHO WORK IN EDUCATIONAL SETTINGS
}

\author{
Dr. Omar França \\ Universidad Católica del Uruguay
}

\begin{abstract}
Resumen: Se abordan algunos dilemas que se le presentan al psicólogo que trabaja en ámbitos educativos, con respecto a la confidencialidad de los datos de los menores que reciben su formación en las instituciones de enseñanza. Se distinguen los datos de tipo psicológico o social, que traen los padres, y que tienen como fuente a profesionales de la psicología y psiquiatría de fuera de la institución, de aquellos otros datos generados por la relación niño-padres-psicólogo educativo.
\end{abstract}

Palabras claves: Etica, confidencialidad, niños, psicólogos educacionales

\begin{abstract}
We present some of the major issues to which educational psychologists are faced at the educational setting with respect to confidentiality and the data of the minors receiving an education. A distinction between social or psychological information that parents provide, shared by psychologists and psychiatrists outside of the institution and the information generated by the child-parent-educational psychologist relationship.
\end{abstract}

Key words: Ethics, Confidentiality, children, educational psychologists

Con frecuencia los psicólogos que trabajan en instituciones educativas se encuentran con dilemas relacionados con la confidencialidad de los datos del niño ${ }^{1}$. Esta incertidumbre en relación a la custodia de los datos de la intimidad del menor puede entablarse entre el psicólogo y las maestras, entre el psicólogo y el director/ a, entre el psicólogo de la institución y otro profesional de fuera de la institución, o entre el psicólogo y los padres.

Desearíamos exponer a continuación algunos criterios que ayuden a los profesionales de la psicología que trabajan en ámbitos educativos a poder prever estos dilemas y resolverlos de forma preventiva, antes que emerjan de forma conflictiva o contraproducente en el ambien- te laboral o antes que se perpetúen prácticas abusivas que van contra los derechos de los niños y de sus padres.

\section{ALGUNOS CONCEPTOS BASICOS}

Puede definirse la confidencialidad como el derecho de todo ser humano a guardar en secreto ciertos datos que conciernen a su persona (França, 1998).

En la tradición ético-jurídica de los países occidentales es una convicción ética normalmente compartida, que todo profesional-como cumplimento de ese derecho de confidencialidad de las personas- debe guardar en secreto las confidencias recibidas de un individuo o ins-

Correspondencia: Omar Franca Tarragó; Doctor. Profesor Agregado. Director del Dpto. de Éticas Aplicadas de la Universidad Católica del Uruguay. Correo electrónico: ofranca@ucu.edu.uy

1 Asumimos el concepto niño, tal como lo establece la Declaración Universal de Derechos del Niño como todo ser humano menor de 18 años. 
titución durante la relación profesional y/o laboral.

Sin embargo, por un lado la sensibilidad de un cierto sector de la sociedad y las posibilidades tecnológicas hoy disponibles, hacen que la confidencialidad sea un valor ético puesto en cuestión.

En particular, queremos referirnos al hecho que se han hecho populares programas de televisión que exhiben, en tiempo real, a millones de personas las intimidades de algunos individuos, haciendo del voyeurismo, -una actitud generalmente considerada patológica- una conducta de alto rating televisivo.

\section{A. LA CONFIDENCIALIDAD COMO DEBER MORAL}

Desde el Juramento Hipocrático, pasando por el imperativo del "secreto de confesión" de los sacerdotes católicos, hasta los modernos códigos de ética profesional y empresarial puede observarse que hay en la práctica de las profesiones dos convicciones morales generalmente planteadas como obligatorias:

1. Deber de defender el derecho de los individuos a que se guarde como secreto toda información que se relacione con su intimidad.

2. Deber de cumplir tal obligación, no de forma absoluta, sino subordinada al imperativo moral superior de no perjudicar a la o las personas inocentes implicadas en la información objeto del secreto.

\section{B. DISTINCIÓN DE TÉRMINOS VINCULADOS}

En relación con este tema hay una serie de conceptos que están relacionados entre sí y que es necesario precisar desde el comienzo. Veamos algunos de ellos.

La Intimidad puede ser definida como el conjunto de características biológicas, psicológicas, éticas, espirituales, socioeconómicas y biográficas de una persona, en la medida que forman parte de su vivencia o conciencia. En ese sentido podemos señalar que la intimidad personal (Novoa Monreal, 1987) está compuesta por:

Aspectos y circunstancias de la vida familiar: nacimientos, esponsales, matrimonio, divorcio, embarazo fallecimiento, vida sexual y amorosa, costumbres, modos de vivir, desgracias, supersticiones, comunicación conyugal, educación de los hijos, costumbres y ritos familiares
Aspectos y circunstancias de la vida intelectual y sus reveses: currículo personal, notas académicas, escritos no publicados, investigaciones o proyectos realizados pero no publicados, ideas, inventos o descubrimientos, intervenciones llevadas a cabo desde el punto de vista profesional

Aspectos y circunstancias de los esparcimientos: actividades y amistades de vacaciones, lugares de vacaciones,

Aspectos y circunstancias del pasado: orígenes familiares, cuestiones concernientes a la filiación y a la descendencia étnica.

Proyectos de futuro: decisiones en proceso de tomarse, posibilidades de trabajo o de estudio.

Vida de relaciones: amistades, odios, comportamientos en el mundo social que pueden originar críticas al individuo si son conocidas públicamente. Cartas o mensajes escritos u orales que no quieran hacerse públicos.

Aspectos y circunstancias económicas: medios económicos, situación tributaria, rentas, cuentas bancarias

Aspectos y circunstancias religiosas y políticas: las ideas, creencias o conductas

Aspectos y circunstancias sanitarias: enfermedades, estados mentales, o momentos de extremo abatimiento, defectos físicos y psíquicos no ostensibles o usualmente ocultados por el individuo. Cumplimiento de funciones fisiológicas corporales o costumbres personales con respecto al cuerpo propio.

Cada uno de estos datos de la intimidad pueden ser objeto de especial custodia, tanto por parte de los psicólogos como por parte de las instituciones donde trabajan los psicólogos

A diferencia del concepto intimidad, podemos entender por privacidad (Bejar, 1989) el derecho de todo ser humano a disponer de un área física, geográfica y social donde ciertos aspectos de su intimidad puedan ser preservados para sí -si así lo desea- sin que hayan intrusiones (físicas, psíquicas o electrónicas) impuestas por otros en ese ámbito que el individuo tiene derecho a reclamar como propio o privado. Aunque no exclusivamente, el concepto de "privacidad" se vincula -en sentido estricto- al ámbito o región físico-geográfico restringido que pertenece "en propiedad" al individuo. En un sentido más amplio, forma parte de la privacidad el derecho a la libre circulación por ámbitos públicos sin que se difunda o registre su conducta o identidad; también incluye el de- 
recho a "disimular" su imagen corporal para permanecer en el anonimato ante terceros, en aquellos ámbitos de libre circulación en los que el individuo no actúa desempeñando roles $^{2}$ o responsabilidades públicas ${ }^{3}$ sino ejerciendo su derecho a la intimidad sin que ésta afecte la vida o los intereses de terceros.

El concepto de confidencialidad, por su parte, se refiere, de forma específica, a un aspecto de la intimidad o de la privacidad: el que concierne a los "datos o informaciones" que otros pueden disponer sobre la persona involucrada. También incluye las informaciones u opiniones privadas que son emitidas por el individuo ante terceros, con la suposición de que su difusión permanecerá controlada por el sujeto que las emite, no solo en cuanto a la extensión de su difusión, sino a la calidad y vía de difusión. Pese a que los límites del término no son aceptados unánimemente y la noción de confidencialidad en algunos casos puede asimilarse a los conceptos que antes hemos distinguido, consideramos que, en un sentido estricto, confidencialidad sería la protección de la comunicación entablada entre personas y el derecho a controlar la información referente a uno mismo que pueda ser difundida a terceros.

Teniendo en cuenta estos tres conceptos, y ciñéndonos al último explicado, las informaciones vinculadas a la confidencialidad del individuo tienen tres niveles concéntricos de menor a mayor exigencia ética de sigilo:

$1^{\circ}$. Nivel más superficial: serían aquellas informaciones respecto a sí mismo que el individuo quiere dar a conocer como parte de su "imagen pública" o socialmente cognoscible. Dentro de este primer nivel los problemas éticos surgen cuando los datos relacionados con la intimidad o privacidad que una persona desea hacer públicos, pueden ser distorsionados por medio de la calumnia o la difamación ${ }^{4}$ afectando, de esa manera, su buena fama u honra ${ }^{5}$. $2^{\circ}$. Nivel intermedio: se incluyen aquí aquellas noticias, opiniones o imágenes que el titular hace partícipes de ellas a determinadas personas de particular confianza mediante manifestaciones orales (por ej. las relaciones profesional-persona), escritas (cartas, etc.) o audiovisuales. Este nivel incluye, por lo tanto, todas informaciones que el sujeto quiere controlar específicamente en relación a su propia imagen corporal o a actitudes correspondientes a ésta, así como al conjunto propio de opiniones, valores o creencias.

$3^{\circ}$. Nivel más íntimo: aquellos eventos o informaciones que el individuo excluye voluntariamente del posible escrutinio por parte de quienes son ajenos a los mismos (diálogo con el profesional, secretos documentales, diarios o notas íntimas).

\section{JUSTIFICACIÓN ÉTICA DE LA CONFIDENCIALIDAD}

En un sentido utilitario podría afirmarse que el deber ético de guardar la confidencialidad tiene un valor instrumental, en la medida que contribuye a facilitar la confianza entre las personas y facilita la revelación de datos por parte de los subordinados a los estratos gerenciales que, de otra manera, no se revelarían.

Desde una ética personalista, (França, 1998) podemos sostener que, aunque la confidencialidad favorece la intimidad interpersonal, el respeto, el amor, la amistad y la confianza, su valor no proviene de que con el cumplimiento de este deber se alcancen estas buenas consecuencias. Al contrario, el derecho al secreto es una condición derivada directamente de la dignidad humana y de nuestro estatuto de ser personas conscientes, libres y comunitarias. Se trata de garantizar un derecho humano básico. En consecuencia toda relación profesional implica -por sus mismas características-, un acuerdo implícito de secreto, que si se

\footnotetext{
${ }^{2}$ Desempeñan roles públicos quienes llevan a cabo actividades profesionalizadas o remuneradas. Entran dentro de esta categoría, en especial, los artistas, deportistas, los profesionales universitarios, etc.

${ }^{3}$ Desempeñan responsabilidades públicas los políticos, los líderes sindicales, los líderes sociales y las autoridades de instituciones religiosas o económicas.

${ }^{4}$ Por esto ciertos regímenes jurídicos protegen la privacidad impidiendo que la "prueba" de la verdad respecto a un hecho imputado a un determinado individuo y acaecido en la vida privada pueda ser llevada hasta las últimas consecuencias en un juicio. En consecuencia, ciertos ataques contra el honor (delitos de injurias) son punibles independientemente de que se haya podido comprobar la veracidad o falsedad de la imputación, por el solo hecho de que el abogado defensor demuestre que son hechos acaecidos en la privacidad.

${ }^{5}$ Honra, según la definición de la Real Academia es la estima y respeto de la dignidad propia, buena opinión y fama adquirida por la virtud y el mérito
} 
rompe, es inmoral, desde el momento en que se quiebra la autonomía, veracidad y la fidelidad merecida por toda persona.

La obligatoriedad de respetar la confidencialidad se derivaría del principio de respeto a la autonomía personal afirmado en el acuerdo implícito que se establece al iniciar cualquier tipo de relación y, en particular, la relación profesional.

Dice, a propósito, la Declaración Universal de los Derechos Humanos:

"Nadie será objeto de injerencias arbitrarias en su vida privada, su familia, su domicilio o su correspondencia, ni de ataques a su honra o a su reputación. Toda persona tiene derecho a la protección de la ley contra tales injerencias o ataques"

En consecuencia, parece convincente pensar que la confidencialidad es una obligación de todo profesional, que está en dependencia con el derecho de la persona u organización a enfocar su autonomía, como crea más conveniente. No existiría autonomía si la persona o la organización no es libre de reservar como íntima una información que le concierne o, por el contrario, difundirla.

No obstante, la confidencialidad no es una obligación absoluta. Cuando está en juego la vida del mismo individuo o la de otras personas, o existe riesgo de que, por guardar el secreto, se provoquen gravísimos daños a la sociedad o a otros individuos concretos, esta norma queda subordinada al principio de Beneficencia, que incluye velar no solo por la integridad de la vida de cada persona sino también por el bien común.

\section{EL PSICOLOGO Y LA CONFIDENCIALIDAD EN AMBITOS EDUCATIVOS}

Tratándose de este particular rol profesional, debemos distinguir dos tipos de informes psicológicos referentes al educando, según su forma de llegada a la institución educativa:

a. informe traído por los padres;

b. informe emitido por el psicólogo de la institución.

\section{A. CUANDO LOS INFORMES PSICOLÓGI- COS SON APORTADOS POR LOS PADRES}

\section{Situación analizada:}

a. En este caso, ellos traen dichos informes porque otros profesionales (psicólogos, psiquia- tras, médicos, asistentes sociales, ministros religiosos) se los han entregado a ellos, como los legítimos responsables del desarrollo psicoafectivo de sus hijos.

b. Los padres por propia iniciativa entregan ese informe al Director/a de la Institución o a las maestras, porque tienen alguna motivación válida para hacerlo.

c. Dichos informes profesionales suelen contener dos tipos de datos concernientes a los hijos:

i. Datos relevantes para la intervención psicopedagógica de "ese" niño en "esa" escuela

ii. Datos que no son relevantes para la intervención psicopedagógica de "ese" niño en "esa" escuela y que, en ocasiones, involucran a otros integrantes de la familia o a hechos sucedidos en el pasado.

\section{Criterios éticos:}

a. Los padres son los que ejercen la patria potestad de sus hijos. En consecuencia, son quienes han de decidir a quien revelan u ocultan, datos referidos a sus hijos. En la circunstancia antes aludida son los padres los que libre y voluntariamente deciden mostrar los informes psicopedagógicos al director/a, a las maestras o al psicólogo de la institución.

Al respecto cabe hacer algunas acotaciones:

a.1. Si bien algunos informes psicológicos o psiquiátricos son difíciles de entender, también lo son todos los informes médicos que suelen hacerse con las nuevas tecnologías de diagnóstico. Las personas que reciben informes médicos complejos tienen derecho a acceder a dichos informes porque son datos que les pertenece. La dificultad para entender ciertos pasajes de un informe clínico complejo concerniente a la salud mental o física de una persona se subsana cuando la persona que no entiende, pregunta al profesional y éste, le aclara sus dudas con las categorías cognitivas apropiadas al implicado.

a. 2 Los pacientes que reciben un informe diagnóstico médico han aprendido -en la relación médico-paciente- que el resultado del día de "hoy", puede no ser válido para el día de "mañana"; cualquier paciente sabe que un análisis de sangre de "hoy" puede ser muy diferente al que me hago dentro de 15 días o dentro de tres meses. Este mismo aprendizaje es el que deben realizar las personas cuando reciben un informe psicodiagnóstico. Y esta misma educa- 
ción -que los médicos han hecho desde siempre- es la que tienen que hacer los psicólogos cuando emiten un determinado informe psicodiagnóstico: deben informar a sus pacientes estos son válidos para un momento del tiempo pero no por tiempo indefinido.

b. Es correcto, desde el punto de vista ético, que un psicólogo (de fuera o de dentro de la institución) le proporcione a los padres los informes psicopedagógicos concernientes a sus hijos, en sobre abierto, porque es derecho de los padres estar enterados -sin excepción- de todo lo que concierne a sus hijos (salvo que hubiese un impedimento demostrado para entender). En ese caso habría que recurrir a informar a un tutor sustituto de la familia u otra fórmula alternativa sobre la que no me detengo en este momento.

Corolario. No es éticamente correcto que un profesional de la psicología o un psiquiatra dirija un informe a otro profesional o a cualquier integrante de una institución, en sobre cerrado, impidiendo que los padres conozcan lo que concierne a sus hijos. Salvo que los padres así se lo hayan autorizado y hayan solicitado que se proceda de esa manera. Lo éticamente correcto es que los informes sean entregados a sus destinatarios: los padres, como legítimos cuidadores de sus hijos. Si en la práctica de ciertos profesionales sucede lo contrario es porque hay una "costumbre" éticamente reprobable por parte de dichos profesionales, que merecería ser cambiada radicalmente. Es claro, además, que existe una aceptación tácita, por parte de los ciudadanos, con respecto a esa forma de proceder. Esto se debería, presumiblemente, a que no han tomado suficiente conciencia de la forma de ejercer sus derechos como legítimos educadores de sus hijos.

c. Dados que los informes psicológicos o psiquiátricos emitidos por profesionales de fuera de la institución no siempre son capaces de diferenciar los datos relevantes para la intervención psicopedagógica del niño en una determinada escuela, puede ser conveniente que el director/a -en trabajo conjunto con el psicólogo- pueda seleccionar de los informes psicológicos o psiquiátricos recibidos de fuera de la institución, aquellos datos concernientes al niño que son relevantes para la intervención pedagógica de "ese" niño en el transcurso de su evolución en "esa" escuela. Estos datos, y no todos, son los que podrían dejarse en la carpeta personal del niño, con libre acceso de las maestras, del director/a, la asistente social o el asistente pastoral del colegio o escuela.

Corolario: los demás datos que no son relevantes para la intervención psicopedagógica de "ese" niño, en "esa" escuela, deberían ser reservados de forma confidencial en el archivo correspondiente donde sólo tenga acceso la director/a (como tutor delegado por los padres) o el psicólogo. Si en ciertos ámbitos educativos se tiene la "costumbre" de proceder de otra manera, merecería ser valorada como éticamente reprobable y debería ser eliminado como procedimiento habitual ${ }^{6}$.

d. Es derecho de los padres tener acceso a la carpeta educativa de sus hijos en todo momento que así lo soliciten. Los datos que conciernen a sus hijos son datos que les pertenecen a ellos, tanto como a la institución. Si bien la propiedad de esos datos es compartida, la institución (maestra o director/a) no tiene derecho a impedir que los padres puedan volver a ver los datos que conciernen a sus hijos, puesto que ellos son los legítimos poseedores de la responsabilidad de educarlos. Cuando un padre encomienda a una institución, la educación de sus hijos, no renuncia a estar informado de todo lo que concierne al desarrollo psicoemocional, social y cultural de sus hijos.

Corolario. la copia de determinados informes deberá ser hecha a costa de los padres, no de la institución.

\section{B. INFORMES EMITIDOS POR EL PSICÓLOGO DE LA INSTITUCIÓN}

\section{Situación analizada:}

a. El informe psicológico es emitido por el psicólogo de la institución a partir de una o varias entrevistas que el psicólogo de la institución ha tenido con el niño o con la familia.

b. En esas entrevistas, el psicólogo accede a una serie de datos concernientes al niño y a su familia que pueden distinguirse:

${ }^{6}$ De esa manera -como me lo ha manifestado la Dra. Mara González- esos datos nos servirán para comprender al niño pero no para etiquetarlo. Se evitaría así el "Efecto Pigmalión" donde el otro acaba siendo y comportándose según la imagen que uno tiene de él. Y todo intento de "salirse" de esa imagen es "penalizado", asumiéndose una predisposición fatalista hacia las posibilidades de cambio del otro. 
i. Datos relevantes para la intervención psicopedagógica de "ese" niño en "esa" escuela

ii. Datos que no son relevantes para la intervención psicopedagógica de "ese" niño en "esa" escuela y que, en ocasiones, involucran a otros integrantes de la familia o a hechos sucedidos en el pasado.

\section{Criterios éticos a tener en cuenta:}

a. Es deber del psicólogo guardar de forma confidencial los datos, concernientes al niño y a su familia, que le hayan sido proporcionados como profesional, en el ejercicio de su actividad profesional, y de los cuales es responsable de custodiar.

b. El psicólogo que trabaja en una institución deberá advertir a los padres, -antes de empezar la entrevista- que aquellos datos que son relevantes para la intervención psicopedagógica de su hijo en "esa" escuela, serán trasmitidos al director/a o a la maestra educadora del niño. Los padres -advertidos de antemano- podrán ejercer su derecho a no revelar al psicólogo, algunos datos que consideran inadecuado que lleguen al conocimiento del director/a de la institución o de las maestras.

c. El psicólogo, por su parte, tiene derecho a reservar para sí, sin revelar a nadie, aquellos datos que, en conciencia, considera que no son relevantes para la intervención psicopedagógica de "ese" niño en "esa" escuela. El psicólogo podrá seleccionar aquellos datos relevantes para la intervención psicopedagógica de "ese" niño en "esa" escuela y elaborar con ellos un informe sistemático que podrá ser incluido en la carpeta escolar del niño. (Como es sabido la carpeta permanece en custodia de la institución y pasa luego a la institución secundaria que recibe al niño cuando éste egresa de la escuela primaria.)

d. Los demás datos podrán:

i. No quedar documentados. El psicólogo no los documenta porque considera que ni siquiera el director/a debe conocer determinados datos que han sido revelados al psicólogo -en su rol de psicólogo- y que no son relevantes para la labor del director/a como tutor, mientras el niño está en la escuela.

ii. Quedar documentados pero con acceso restringido única y exclusivamente al director/a de la institución. Entendemos que si los padres -luego de advertencia previa- han aceptado que el psicólogo permitiría el acceso de los datos al director, por ser el tutor de su hijo en el tiempo de escuela, dichos datos pueden ser escrutados por el director/a, si lo necesitare para ejercer mejor su función de tutor delegado del hijo, mientras está en la escuela.

iii. Los datos que no son relevantes para la intervención psicopedagógica de "ese" niño en "esa" escuela, son confidenciales y no deben quedar al libre escrutinio de quien no sea el psicólogo o el "tutor" delegado (director/a) en la institución. Estos datos jamás deberán integrar la carpeta personal del niño a la que accederán las maestras u otros miembros de la institución.

\section{EN RESUMEN:}

La confidencialidad es un deber de todo profesional que es la contrapartida del derecho a preservar la intimidad que tienen todas las personas. La responsabilidad de la custodia de la intimidad de los niños corresponde, en primer lugar, a los padres, en segundo lugar al tutor delegado (director/a) de la institución y a todo profesional que accede a esos datos.

El psicólogo por su particular rol profesional accede a ciertos datos que pertenecen a la intimidad del niño y de su familia, que pueden ser relevantes para el desarrollo educativo y emocional del niño. Esos datos son los que podrían figurar en la carpeta del menor, una vez que el padre dé su consentimiento después de haber sido adecuadamente informado de ese procedimiento y antes que revele datos de la intimidad del niño o de la familia, a algún miembro de la institución o profesional que trabaja en ella.

Los demás datos relativos a la intimidad del niño y de su familia, que no son relevantes para el desarrollo educativo y emocional del niño, deberán ser custodiados de forma confidencial. Si se trata de datos concernientes a la intimidad del menor, surgidos por la intervención del psicólogo de la institución, deberá ser el psicólogo el que custodie dichos datos. Si los padres solicitan que se revelen, deberán ser revelados. La dirección de la institución no puede disponer de esos datos sin el consentimiento de los padres y del psicólogo. 


\section{REFERENCIAS}

Beauchamp,T.\& J.F.Childress, (1994). Principles of Biomedical ethics. New York: Oxford Univ.Press

Becker, L.C. (1993). Secrecy. En: Encyclopedia of Ethics. London: Garland Publishing. Inc.

Bejar, H., (1989). Individualimo, privacidad e intimidad: precisiones y andaduras. En: Castilla del Pino, C. De la intimidad. Madrid: Crítica, 33-57.

Castilla del Pino, C. (1989). De la intimidad. Madrid: Crítica.

Childress, J. F. (1990). The place of autonomy in Bioethics Hast.Cent.Rep 20:1, 12-16.
Engelhardt, T. H. (1986). The Foundations of Bioethics Oxf.Univ.Pres. New Cork.

França, O, (1996). Ética para Psicólogos: Introducción a la Psicoética. Bilbao: Desclée.

França, O, (1998). Introducción a la Ética Profesional. Asunción: Paulinas.

Gracia, D. (1989). Fundamentos de Bioética. Madrid: Eudema.

Novoa Monreal, E. (1987). Derecho a la vida privada y libertad de información. Méjico: Siglo XXI.

Reich, W. (1995). Confidentiality. En: Encyclopedia of Bioethics. New York: MacMillan.

Vidal, M. (1993). Bioética. Madrid: Tecnos. 